\title{
A de novo insertion, detected prenatally, with normal phenotype
}

\author{
A F Hashish, N A Monk, A J Watt, R J M Gardner
}

A 29 year old woman presented for amniocentesis because of a low maternal serum $\alpha$ fetoprotein. She had had eight miscarriages over an 11 year period. She had one normal son from her second pregnancy. She, her husband, and the son all had a normal karyotype.

The amniocentesis showed an interchromosomal insertion with the non-mosaic karyotype $46, \mathrm{XX}$, dir ins $(9 ; 3)(\mathrm{q} 22.1 ; \mathrm{p} 14.2 \mathrm{p} 25.1)$. She continued the pregnancy and was delivered of a $4240 \mathrm{~g}$ apparently normal female baby in whom the same karyotype was confirmed on peripheral blood analysis. A partial karyotype is shown in the figure. At $4 \frac{1}{2}$ months, a paediatric assessment showed normal growth indices, normal systems examination, and her neurodevelopment was at the 5 month level. Although neurodevelopmental progress is at present very satisfactory, some years' follow up will yet be necessary to enable definitive assessment of intellectual status.

De novo apparently balanced rearrangements detected at prenatal diagnosis pose a dilemma. Most simple reciprocal translocations are associated with a normal outcome, and most complex rearrangements with an abnormal baby. An insertion, which involves three breakpoints, could be considered somewhat intermediate between simple and complex in this context. Numerous cases are on record of phenotypically normal heterozygotes for a familial balanced insertion (ascertained, for the most part, through having had recombinant offspring or repeated pregnancy loss). ${ }^{1}$ Evidently, the normality of phenotype of these heterozygotes indicates intact genetic function. Nevertheless, the precedents provided by the more common types of rearrangement suggest that perturbation of genetic function could in some instances result from the mechanics of the formation of an insertion. However, we know of only two reports which might exemplify this circumstance. From the early days of chromosome banding, Gray et $a l^{2}$ described a severely retarded and dysmorphic baby with a de novo insertion, although this case may, in fact, not be relevant as the authors postulated the rearrangement could be unbalanced with the segment distal to the break-

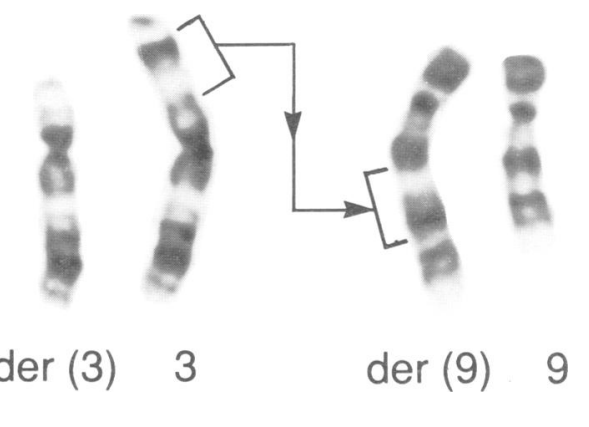

Partial karyotype of the 9;3 insertion (peripheral blood). The segment of chromosome 3 inserted into chromosome 9 is indicated.

point in the 'donor chromosome' possibly lost. Roberts et $a l^{3}$ reported a familial insertion associated with, and possibly causative of, neuropsychiatric dysfunction. Warburton ${ }^{4}$ reported a de novo insertion detected at amniocentesis, but with termination being performed on the grounds of haemoglobinopathy.

Given that our best guess was for a 'substantial' probability of a normal outcome in the present case, and with the couple's decade long attempt for a successful pregnancy, it was for them a fairly straightforward decision to continue.

We are unaware of any other report of a de novo balanced insertion detected at prenatal diagnosis and followed up postnatally. Such cases warrant reporting in order that genetic counselling may be provided from a more secure base than at present.

We thank Dr B J Taylor who did the paediatric assessment.

1 Abuelo DN, Barsel-Bowers G, Richardson A. Insertional translocations: report of two new families and review of the literature. Am ₹ Med Genet 1988;31:319-29.

2 Gray JE, Syrett JE, Ritchie KM, Elliott WD. An interstitial translocation: chromosome no. 1p to 4q. Lancet 1972; ii: $92-3$.

3 Roberts SH, Cowie VA, Singh KR. Intrachromosomal insertion of chromosome 13 in a family with psychosis and tion of chromosome 13 in a family with psychosis and
mental subnormality. $\mathcal{f}$ Ment Defic Res 1986;30:227-32.

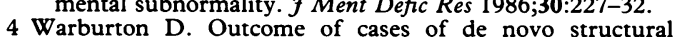
rearrangements diagnosed at amniocentesis. Prenat Diagn rearrangemen 